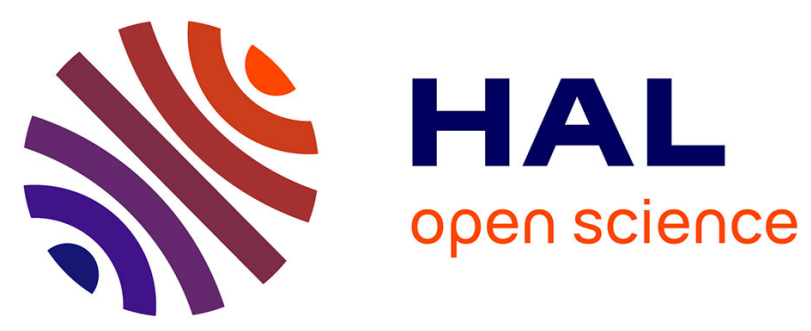

\title{
Study of structural and ferromagnetic properties of pure and Cd doped copper ferrite
}

\author{
Radheshyam Rai, Kavita Verma, Seema Sharma, Swapna S. Nair, Manuel \\ Almeida Valente, Andrei L. Kholkin, Nikolai A. Sobolev
}

\section{- To cite this version:}

Radheshyam Rai, Kavita Verma, Seema Sharma, Swapna S. Nair, Manuel Almeida Valente, et al.. Study of structural and ferromagnetic properties of pure and $\mathrm{Cd}$ doped copper ferrite. Journal of Physics and Chemistry of Solids, 2011, 72 (7), pp.862. 10.1016/j.jpcs.2011.04.002 . hal-00757445

\section{HAL Id: hal-00757445 \\ https://hal.science/hal-00757445}

Submitted on 27 Nov 2012

HAL is a multi-disciplinary open access archive for the deposit and dissemination of scientific research documents, whether they are published or not. The documents may come from teaching and research institutions in France or abroad, or from public or private research centers.
L'archive ouverte pluridisciplinaire HAL, est destinée au dépôt et à la diffusion de documents scientifiques de niveau recherche, publiés ou non, émanant des établissements d'enseignement et de recherche français ou étrangers, des laboratoires publics ou privés. 


\section{Author's Accepted Manuscript}

Study of structural and ferromagnetic properties of pure and $\mathrm{Cd}$ doped copper ferrite

Radheshyam Rai, Kavita Verma, Seema Sharma, Swapna S. Nair, Manuel Almeida Valente, Andrei L. Kholkin, Nikolai A. Sobolev

PII: S0022-3697(11)00074-6

DOI: doi:10.1016/j.jpcs.2011.04.002

Reference: PCS 6440

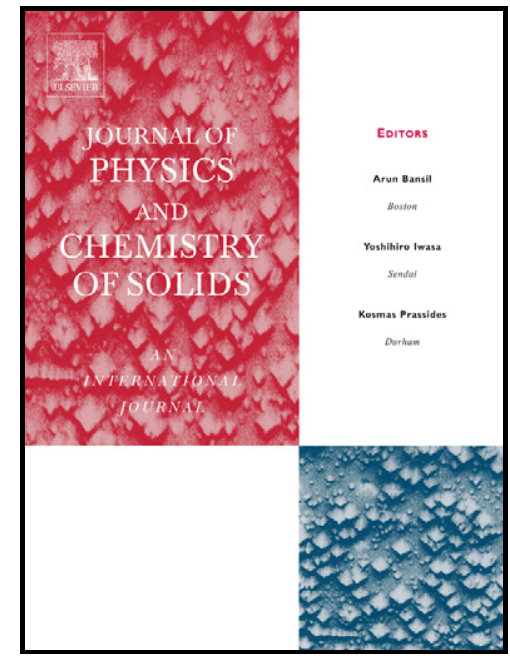

www.elsevier.com/locate/jpcs

To appear in: $\quad$ Journal of Physics and Chemistry of Solids

Received date: $\quad 15$ October 2010

Revised date: $\quad 18$ March 2011

Accepted date: $\quad 3$ April 2011

Cite this article as: Radheshyam Rai, Kavita Verma, Seema Sharma, Swapna S. Nair, Manuel Almeida Valente, Andrei L. Kholkin and Nikolai A. Sobolev, Study of structural and ferromagnetic properties of pure and Cd doped copper ferrite, Journal of Physics and Chemistry of Solids, doi:10.1016/j.jpcs.2011.04.002

This is a PDF file of an unedited manuscript that has been accepted for publication. As a service to our customers we are providing this early version of the manuscript. The manuscript will undergo copyediting, typesetting, and review of the resulting galley proof before it is published in its final citable form. Please note that during the production process errors may be discovered which could affect the content, and all legal disclaimers that apply to the journal pertain. 


\title{
Study of structural and ferromagnetic properties of pure and Cd doped copper ferrite
}

\author{
Radheshyam Rai ${ }^{a}$, Kavita Verma ${ }^{b}$, Seema Sharmab ${ }^{b}$ Swapna S. Nair ${ }^{c}$ \\ Manuel Almeida Valente ${ }^{c}$, Andrei L. Kholkin ${ }^{a}$ and Nikolai A. Sobolev ${ }^{c}$ \\ ${ }^{a}$ Department of Ceramics and Glass Engineering and CICECO, University of Aveiro, 3810-193 Aveiro, \\ Portugal \\ ${ }^{b}$ Ferroelectrics Research Laboratory, Department of Physics, A.N. College, Patna-800013, India \\ 'Departamento de Fisica, I3N, Universidade de Aveiro, Campus Universitario de Santiago, 3810-193 \\ Aveiro, Portugal
}

\begin{abstract}
This report presents the synthesis of copper cadmium ferrite $\left(\mathrm{Cu}_{1-x} \mathrm{Cd}_{x} \mathrm{Fe}_{2} \mathrm{O}_{4}, \mathrm{x}=0.3,0.4,0.5\right.$, 0.6 and 0.7 ) by citrate precursor method and its subsequent characterization by using X-ray diffraction (XRD), differential scanning calorimetry, infrared spectroscopy and ferromagnetic resonance. XRD results confirm the single cubic spinel phase formation with the particle size of $40 \mathrm{~nm}$, which decreased up to $20 \mathrm{~nm}$ with increase in $\mathrm{Cd}$ content, while the lattice parameter increased with increase in $\mathrm{Cd}$ content. A significant change in the magnetic properties was observed in $\mathrm{CuFe}_{2} \mathrm{O}_{4}$ system with $\mathrm{Cd}$ doping. The line width and resonance field variation against change in temperature is noted and the data is fitted to the Linearlized model (LM) and Smit and Beljers (SB) model to find out the parameters. The results recorded from the SB approach are in good agreement to that observed in the magnetic measurements carried out by vibrating sample magnetometer (VSM) techniques.

Keywords: Ceramics; Magnetic materials; Chemical synthesis; X-ray diffraction; Magnetic properties

*Corresponding author: Radheshyam Rai

Email: radheshyamrai@ua.pt

Telephone Numbers: 00351-962782932

Fax Numbers: 00351-234425300
\end{abstract}




\section{Introduction}

The synthesis of nanostructured magnetic materials has become an important area of research since such materials are attracting growing interest in technological applications of modern magnetic materials which reveal a range of fascinating phenomena [1-4]. Especially, nanoscale magnetic ferrites are of particular interest due to their unique combination of electronic and magnetic properties [4-6]. Transition metal oxides $\left(\mathrm{MFe}_{2} \mathrm{O}_{4}\right)$ are magnetic materials with cubic spinel structure and have been extensively used in various technological applications in the past decade. Indeed, owing to their high electrical resistivity that implies low losses due to parasitic currents, and to their susceptibility, they are preferred in application ranging from transformers to magnetic heads. In addition, their high permeability in the r.f. frequency region, make polycrystalline ferrites suitable for an increasing number of electronic devices [7]. Cubic spinel ferrites with space groups $\mathrm{Fd} 3 \mathrm{~m}$, have been the subject of many recent investigations due to cation distribution. The diversity in properties of ferrites has paved the way for the development of a wide variety of ferrites for various applications as permanent magnets, electrical and electronic compounds. Copper ferrite is an inverse ferromagnetic spinel in which a small amount of $\mathrm{Cu}^{2+}$ ions migrate from octahedral B to tetrahedral A sites. The degree of inversion $\left(\mathrm{Cu}_{\delta} \mathrm{Fe}_{1-\delta}\right)^{\mathrm{A}}\left[\mathrm{Cu}_{1-\delta} \mathrm{Fe}_{1+\delta}\right]^{\mathrm{B}} \mathrm{O}_{4}$, (where $\delta$ is the inversion parameter and $\delta=0$ and 1 stand for the inverse and normal cases, respectively) i.e the fraction of cupric ions at B-sites strongly depends on the preparation technology [8-10]. Incorporation of zinc and cadmium ions strongly affects the magnetic properties of ferrospinel [11] due to its well known preferences for tetrahedral surroundings. It has been reported that cadmium substituted $\mathrm{Cu}$ ferrites behaves as n-type semiconductors and the seebeck coefficient gradually decreases with increase in cadmium content $[12, \mathbf{1 3}]$. The physical and chemical properties of these materials can be tuned by controlling the particle size, shape and the inter particle interactions [14-17].

Ferromagnetic resonance (FMR) is a spectroscopic technique to probe the magnetization of ferromagnetic materials. It is a standard tool for probing spin waves and spin dynamics, so it is a powerful characterization technique for magnetic nanoparticle systems [18-22]. One of the advantages of FMR over 
conventional magnetization measurements is that it yields information on the dynamics of the system. FMR gives contribution from the each component in the assembly. This is a powerful tool in probing mixture systems with ferro/ferri and paramagnetic particles. The temperature variation of the FMR spectra provide valuable information on magnetic systems, especially in an assembly of magnetic nano particles. One of the first attempts to understand the temperature variation of the FMR spectra was done by Biasi and Devezas [18]. More recently Raikher and Stepanov [23] developed a formalism to consider superparamagnetic resonances in the limit of large Zeeman interaction as compared to the anisotropy energy. They reported that the shape anisotropy has the same functional dependence as a uniaxial anisotropy term, which is different from what was originally predicted [20]. Only recently [21-23] these theories have been applied to systems to obtain the physical parameters like anisotropy and magnetic moment, from the line shape of the FMR curves. In one such attempt, while probing $\mathrm{Co} / \mathrm{Ag}$ clusters, Sánchez et al. [22] showed that FMR and DC magnetization yield consistent results regarding the particle volume and anisotropy. These theories rely on the assumption that the effective field acting on each particle can be considered as the addition of the applied field and the anisotropy field modified by thermal excitations. However, large volume systems, such as thin films, where the resonance field is non-linear in the applied field [24-25] these theories cannot be directly applied.

In a recent publication, E. de Biasi et al. [26] has given detailed information on thermal fluctuations in the FMR modeling of ferromagnetic single domain nanoparticles with uniaxial shape anisotropy in which the results obtained from the nonlinear SB model and LM model were compared assuming the $\Delta \mathrm{H}_{0}$ as a constant near to room temperature and high temperature. The paper provides emphasis on the interpretation of the observed quantities (FMR line shape, line width and resonance field) in terms of the particle parameters (magnetic moment, anisotropy, and intrinsic FMR line width).

From the simulations performed in the abovementioned article, it is clear that the usual "peak-to-peak" line width, $\Delta \mathrm{H}_{\mathrm{pp}}$ obtained from the FMR spectra is not unambiguously defined at low temperature, as there are two peaks in the low (high) field side for the prolate (oblate) ellipsoid. For the purpose of deriving the 
anisotropy from observed line width, $\Delta \mathrm{H}_{\mathrm{pp}}$ should be obtained from the peaks most widely separated. The results obtained from the Smit-Beljers (SB) formulation is compared with a linearized model for the resonant field. In the limit of small anisotropy both results coincide. At moderate and large anisotropy the RMS deviation indicates clear discrepancies between these two models. In that it is shown that the anisotropy field can be directly deduced from the low temperature peak-to-peak line width analysis and the particle magnetic moment can be estimated after subtraction of the intrinsic line width contribution. In our system of Cd doped copper ferrite, FMR signal and resonance field was recorded at different temperatures. Authors followed a similar approach as provided in [26] for the calculation of $\Delta \mathrm{H}_{\mathrm{pp}}$, anisotropy and magnetic moment. The line shape observed in our system exactly follows the simulated curves for the prolate ellipsoid [25] in which the line doubling is more towards the low field side.

In the present investigation we have prepared nano structured $\mathrm{Cu}_{1-\mathrm{x}} \mathrm{Cd}_{\mathrm{x}} \mathrm{Fe}_{2} \mathrm{O}_{4}$ (where $\mathrm{x}=0.3,0.4,0.5$, 0.6 and 0.7 ) system through thermal decomposition of mixed metal citrates. We attempt to determine the effect of copper ferrite spinel formation and the role of cadmium content on structural and magnetic properties of these ferrospinels.

\section{Experimental details \\ 2.1 Materials Synthesis}

Polycrystalline samples of $\mathrm{Cu}_{1-\mathrm{x}} \mathrm{Cd}_{\mathrm{x}} \mathrm{Fe}_{2} \mathrm{O}_{4}$ with $\mathrm{x}=0.3,0.4,0.5,0.6$ and 0.7 were prepared by citrate precursor method. The technological advantage of this method is that mixing of the metal ions takes place on an atomic scale in the solution state during the initial stages of preparation giving rise to homogeneous mixtures. The chemical precursors used in the preparation were copper nitrate, cadmium nitrate, Iron (III) nitrate and citric acid. The chemicals were accurately weighed according to the required stoichiometric proportion. An aqueous solution of Fe (III) citrate was prepared in distilled water. Copper nitrate and Cadmium nitrate was separately mixed with citric acid and few drops of distilled water and heated at about $40^{\circ} \mathrm{C}$ for an hour to form the metal-citrate complex. These solutions were then added slowly to the Fe (III) citrate solution with constant 
stirring to avoid precipitation and obtain a homogeneous mixture. The clear solution of brown-colored citrate mixture was obtained with no precipitation and no segregation of phases. This mixture was gradually heated at $60^{\circ} \mathrm{C}$ on a hot plate with magnetic stirrer to obtain slurry. The precursor was obtained by drying it in the oven. This solid precursor was in the form of a uniformly colored brown transparent glassy material containing the cations homogeneously mixed on an atomic scale [27]. This dried citrate mixture was calcined in muffle furnace for 4 hours at $600^{\circ} \mathrm{C}$ to obtain a ferrite of the compound $\mathrm{Cu}_{1-\mathrm{x}} \mathrm{Cd}_{\mathrm{x}} \mathrm{Fe}_{2} \mathrm{O}_{4}$. The calcined compounds were grounded in a mortar pestle to obtain fine powder. The fine powders were used to characterize the structural and magnetic properties of the compound.

\subsection{Structural Characterization}

The X-ray diffraction pattern of the compounds was recorded at room temperature using X-ray powder diffractometer with $\mathrm{CuK}_{\alpha}$ radiation $(\lambda=1.5418 \AA)$ in a wide range of Bragg angles $2 \theta\left(20^{0} \leq 2 \theta \leq 60^{0)}\right.$ at a scanning rate of $2^{0} \mathrm{~min}^{-1}$. Fourier Transform Infrared (FTIR) spectra of dried samples were recorded on the Thermo NICOLET 5700 FTIR spectrophotometer in the range of $4000-400 \mathrm{~cm}^{-1}$ in ATR (attenuated total reflectance) mode.

\subsection{Magnetic Characterization}

FMR measurements were done using an $X$-band electron paramagnetic resonance spectrometer Bruker ESP 300 E. The resonance spectra were recorded in varying magnetic field mode for the Cd doped copper ferrite samples at a constant microwave frequency of $9.48 \mathrm{GHz}$. The other parameters are: microwave power $=0.5 \mathrm{~mW}$; Gain $=1 \times 10^{2 ;}$ Cylindrical quartz sample holder. The recording of the resonance spectra were repeated for different temperatures starting from $125 \mathrm{~K}$ to $400 \mathrm{~K}$ in a step of $10 \mathrm{~K}$ in order to study the variation of the line shape, resonance field and line width with respect to the change in temperature. The magnetic data were recorded with the help of vibrating sample magnetometer (VSM) (Cryogenic).

\subsection{Thermal Characterization}


Differential Scanning Calorimetry (DSC) and Thermal Gravimetric Analysis (TGA) studies were carried out from room temperature to $800^{\circ} \mathrm{C}$ at a heating rate of $5^{\circ} / \mathrm{min}$ by NETZSCH (GMBH). STA449C software was used for the analysis of these studies.

\section{Results and discussion}

\subsection{Structural Analysis}

The X-ray diffractograms of $\mathrm{Cu}_{1-\mathrm{x}} \mathrm{Cd}_{\mathrm{x}} \mathrm{Fe}_{2} \mathrm{O}_{4}$ ferrite system (Fig. 1) reveal the single-phase spinel structure without any ambiguous reflection. The experimentally observed $\mathrm{d}$ spacing values and relative intensities are in well agreement with those reported in the ASTM powder diffraction files. The calcined powder samples show XRD peaks at $d=2.97,2.59,2.50,2.06$ and $1.59 \AA$ and they are in good agreement with the standard XRD pattern, JCPDS (34-0425) of $\mathrm{CuFe}_{2} \mathrm{O}_{4}$. The lattice parameters are obtained by fitting at least seven diffraction peaks using standard least square refinement methods. The lattice parameters are in the expected range with the lattice constant of $\mathrm{CuFe}_{2} \mathrm{O}_{4}[28]$ and $\mathrm{CdFe}_{2} \mathrm{O}_{4}$ [29] at either end. Lattice parameter increases linearly with the increase of cadmium content. This could be attributed, as expected, to the large ionic radius of $\mathrm{Cd}^{2+}\left(0.78 \mathrm{~A}^{\circ}\right)$ which when substituted in the lattice resides on the tetrahedral site and replaces the smaller $\mathrm{Cu}^{2+}\left(0.57 \mathrm{~A}^{\circ}\right)$ or $\mathrm{Fe}^{3+}\left(0.49 \mathrm{~A}^{\circ}\right)$ ions from the tetrahedral to the octahedral site [30-31]. No other phase was observed in the XRD pattern indicating that no chemical transformation took place during the heat treatment. The XRD graph indicated that the synthesized powders contain nanosized crystallites. The variation of average particle size and lattice parameter with $\mathrm{Cd}$ content is shown in Fig. 2. The average particle size decreases with $\mathrm{Cd}$ content, which is attributed to the diffusion phenomenon involving $\mathrm{Cd}$, oxygen vacancies and porosity that hampers the grain growth.

\subsection{FTIR Analysis}

Fig. 3 shows FTIR spectrum recorded from the dried powder of CuCdFerrite prepared by citrate precursor method. The representative spectra of nanoparticles obtained manifests absorption peaks located at about $1160,1236,1309,1434,1614$ and 1722 in the region of $1000-1750 \mathrm{~cm}^{-1}$. The absorption peak at around 
$1160-1309 \mathrm{~cm}^{-1}$ can be assigned as absorption peaks of aliphatic amines. The peaks at $3400 \mathrm{~cm}^{-1}$ and $2900 \mathrm{~cm}^{-1}$ were assigned to the stretching vibrations of primary and secondary amines. The as-synthesized sample shows characteristic absorptions of ferrite phase with a strong absorption around $1600 \mathrm{~cm}^{-1}$ and weak absorption in the range $1000-1450 \mathrm{~cm}^{-1}$. This difference between the band positions is expected because of the difference in the $\mathrm{Cd}^{+}-\mathrm{O}_{2}{ }^{-}$distance for the octahedral and tetrahedral compounds. There are weak and broad absorptions around 2800 and $3500 \mathrm{~cm}^{-1}$ corresponding to the presence of small amount of residual carbon in the samples. Heat treatment led to the disappearance of these absorptions indicating complete removal of residual carbon from the sample.

\subsection{Thermal Analysis}

The thermal decomposition studies of the samples shows that all the mixtures decompose in the temperature range $40^{\circ} \mathrm{C}$ to $350^{\circ} \mathrm{C}$. A typical DTA-TG thermogram for the thermal decomposition of $\mathrm{CuCdFe}_{2} \mathrm{O}_{4}$ in air is shown in Fig. 4. It can be observed that the mixture loses its weight in three well defined steps giving at complete decomposition a total weight loss of $85 \%$ which corresponds to the formation of copper cadmium ferrite; $\mathrm{CuCdFe}_{2} \mathrm{O}_{4}$. The first step starts at $40^{\circ} \mathrm{C}$ and is characterized by an endothermic peak at $80^{\circ} \mathrm{C}$. The weight loss that accompanied this step amounts to $20 \%$ on the TGA curve due to vaporization of water. The mixture is thermally stable upto $140^{\circ} \mathrm{C}$ after which the main decomposition step occurs. This step exhibits a weight loss of $40 \%$ at $150^{\circ} \mathrm{C}$ which closely corresponds to the complete decomposition of iron (III) nitrate with the formation of $\mathrm{Fe}_{2} \mathrm{O}_{3}$. The endothermic DTA peak at $140^{\circ} \mathrm{C}$ was swamped by the large exothermic decomposition occuring at $150^{\circ} \mathrm{C}$. The third step accounts for the exothermic decomposition of copper nitrate and cadmium nitrate with the formation of $\mathrm{CuO}$ and $\mathrm{CdO}$, respectively. This step is associated with $25 \%$ weight loss at $264^{\circ} \mathrm{C}$. No further weight loss was observed even by raising the temperature upto $800^{0} \mathrm{C}$.

\subsection{Magnetic Resonance Analysis}


One of the typical characteristic of a resonance spectrum is the resonance field, $\mathrm{H}_{\mathrm{r}}$. The resonance spectra (the first derivative of the microwave power absorption) of $\mathrm{Cu}_{1-\mathrm{x}} \mathrm{Cd}_{\mathrm{x}} \mathrm{Fe}_{2} \mathrm{O}_{4}$ as a function of the magnetic field in different temperatures are shown in Fig. 5 (a,b,c), where $\mathrm{x}$ varies from 0.3 to 0.7 . Resonance field is determined by fitting the experimental resonance line to Lorentzian (derivative) curve. The temperature dependence of the apparent peak-to-peak line width and that of the apparent resonance field for all the samples are given in Fig. 6 and Fig. 7 respectively. It is observed that as the temperature decreases the spectra are broadened and their apparent centre shifts towards lower magnetic fields (Fig. 6-8). A marked decrease in the peak-to-peak amplitude is observed at the same time. The observations are similar to that reported earlier in gamma $\mathrm{Fe}_{2} \mathrm{O}_{3}$ system [32]. This behaviour is typical of a superparamagnetic particle (Normally the resonance field is a function of the magnetic moment of the sample which increases with cooling as thermal randomisation is less. Hence the resonance field is expected to increase with the decrease in temperature). In the case of a random distribution of anisotropy axes each nanoparticle has its own $\mathrm{H}_{\mathrm{r}}$. Therefore, the resonance field of an ensemble of randomly oriented non-interacting particles cannot be clearly defined in the spectrum. Many previous works report $\mathrm{H}_{\mathrm{r}}$ to decrease when $\mathrm{T}$ is lowered in nanoparticle systems. In an attempt to explain the observation of the reduction of $\mathrm{H}_{\mathrm{r}}$ from the $\mathrm{o}=\mathrm{g}$ value, Berger et al.[33] proposed that this effect is due to the damping of the magnetization, finding the Landau-Lifshitz equation to best describe the observed spectra. Verdes et al. [34] showed with the help of monte carlo simulations that exchange effects can give a significant shift in the resonance line, in all cases lowering the observed resonance field.

One can see in Fig. 8 that both the resonance field and the line width can be fitted by assuming Lorentzian (derivatives) except for small discrepancies showing the absence of other phases in the sample: The discrepancy could be due to the neglect of the temperature dependence of the magnetic parameters $M$ and $K_{1}$ ( first-order anisotropy constant). The apparent peak-to-peak line width variation with temperature is shown in Fig. 6. The temperature dependence of the individual line width is rather complicated. At very low temperatures the Langevin function becomes saturated for the majority of the nano particles so that the main 
mechanism of this dependence is the thermal fluctuation induced modulation of the magnetocrystalline anisotropy energy.

$$
\Delta_{T}=\Delta_{0} G\left(\frac{K_{1} V_{s}}{k T}\right)
$$

provides a good estimate of the experimental low temperature line widths. The $\Delta_{\mathrm{T}}$ value at $\mathrm{T}=0$ (the greatest limiting line width $\Delta_{0}$, corresponds to the relaxation frequency $5.3 \times 10^{9} \mathrm{~s}^{-1}$ (biggest nanoparticle in the statistical assembly under consideration have a diameter of $230 \AA$ ). This value of relaxation frequency can be compared to that of the reported value for gamma $\mathrm{Fe}_{2} \mathrm{O}_{3}$ at low temperature [26].

$\Delta \mathrm{H}_{\mathrm{pp}}$ was plotted for all the samples considering the most widely separated peaks (the lowest maximum and the minimum) for a prolate ellipsoid as a function of $\mathrm{H}_{\mathrm{A}}$ for different intrinsic widths $\mathrm{SB}$ (bottom) approach [26]. The line shape and the temperature variation of the line shape, resonance field and the peak to peak line width exactly follows the simulated curves for a prolate ellipsoid by the SB approach [26]. So the most relevant one is the temperature variation of the peak-to-peak width. Hence the exchange effects are not considered in the calculations.

Fig. 7 provides experimental recording of $\Delta \mathrm{H}_{\mathrm{pp}}$ as a function of temperature for different compositions of $\mathrm{Cd}$ doped copper ferrite samples. At high temperature $\Delta \mathrm{H}_{\mathrm{pp}}$ approaches asymptotically the intrinsic width value, corresponding to a Lorentzian line shape. Therefore from experiments $\Delta \mathrm{H}_{0}$ and $\mu$ can be extracted (Table 1). For the calculation of $\mu$ and $\Delta \mathrm{H}_{0}$, from $\Delta \mathrm{H}_{\mathrm{pp}}$, the simple LM approach was adopted. Assuming $\Delta \mathrm{H}_{0}$ constant in the high- $\mathrm{T}$ limit, the observed $\Delta \mathrm{H}_{\mathrm{pp}}$ had a $1 / \mathrm{T}^{2}$-dependence, from which $\mu$ is determined [26] for all the copper ferrite samples with varying cadmium concentrations. The values of the magnetic moment and the anisotropy field are very much in agreement with the values calculated from the VSM data (Table1). Hence the analysis of the FMR signal in a system with varying magnetic moment shows that the SB approach can be used 
for the determination of an ensemble of magnetic particles especially in ferrites with more or less homogeneous particle size or with a system with very small variation in the particle size.

\section{Conclusions}

We have reported the structural, microstructural and FMR properties of cadmium doped copper ferrite ceramics, which was synthesized by citrate precursor method. The average particle size of copper ferrite was $40 \mathrm{~nm}$, which on doping with $\mathrm{Cd}$ decreased to $20 \mathrm{~nm}$. Thermal treatment of the ferrite samples led to the disappearance of the absorption peaks in the DSC study indicating the complete removal of residual carbon from the sample. All the samples exhibited ferromagnetic nature at room temperature with appreciable value of remanent magnetization. Switching of magnetic moments from a higher value to zero is observed for all the samples at a specific applied magnetic field. The line width and resonance field variation against change in temperature is fitted with the LM and SB model. A system with varying magnetic moment (Cd doped copper ferrite which is pre-characterised magnetically by VSM) is used as a nanoparticle system. The results recorded from the SB approach are in good agreement to that observed in the magnetic measurements by VSM. The anisotropy field was directly deduced from the low temperature peak-to-peak linewidth analysis and the particle magnetic moment was estimated after substraction of the intrinsic linewidth contribution. FMR signal in a system with varying magnetic moment shows that the SB approach can be used for the determination of an ensemble of magnetic particles especially in ferrites. 


\section{References}

[1] Q.A. Pankhurst and A.J. Pollard, J. Phys. Conds. Mat. 5 (1993) 8487.

[2] Q.A. Pankhurst, J.S. Connolly, K. Jones and J. Dobson, J. Phys. D: Appl. Phys. 36 (2003) R167.

[3] J. Philip, G. Gnanaprakash, T. Jayakumar, P.K. Sundaram and B. Raj Surfactant and Colloidal Interaction 36 (2003) 9230.

[4] I.I.S. Lim, P.N. Njoki, H.Y. Park, X. Wang, L. Wang, D. Mott and C.J. Zhong, Nanotechnology 19 (2008) 305102.

[5] W.F.J. Fontijn, P.J. Van der Zaag, M.A.C. Devillers, V.A.M. Brabers and R. Metselaar, Phys. Rev. B 56 (1997) 5432.

[6] J. Philip, P.D. Shima and B. Raj, Appl. Phys. Lett. 92 (2008) 043108.

[7] L. Suber, R. Zysler, A. Garc'1a Santiago, D. Fiorani, M. Angiolini, A. Montone and J.L. Dormann, Mater. Sci. Forum 937 (1998) 269.

[8] Q. Li, Y. Wang and C. Chang, J. Alloys and Comps. 505 (2010) 523-526.

[9] A.B. Gadkari, T.J. Shinde and P.N. Vasambekar, Mater. Character. 60 (2009) 1328-1333.

[10] H. Su, H.W. Zhang, X.L. Tang and Y.L. Jing, Trans. of Nonferrous Metals Soc. China 21 (2011) 109-113.

[11] K.B. Modi, P.V. Tanna, S.S. Laghate and H.H. Joshi, J. Mater. Sci. Lett. 19 (2000) 1111.

[12] D. Ravindar, S.S. Rao and P. Shalini Mater. Lett. 57 (2003) 4040.

[13] P.K. Nayak, Mat. Chem. and Phys. 112 (2008) 24.

[14] H. Deng, H. Chen and H. Li, Mat. Chem. and Phys. 101 (2007) 509.

[15] G. Viau, R. Brayner, L. Poul, N. Chakroune, E. Lacaze, F.F. Vincent and F. Fi'evet, Chem. Mater. 15 (2003) 486.

[16] B. Wiley, T. Herricks, Y. Sun and Y. Xia, Nano Lett. 4 (2004) 1733.

[17] J.Z. Jiang, G.F. Goya and H.R. Rechenberg, J. Phys.: Condens. Matter. 11(1999) 4063.

[18] J.L. Dorman, D. Fiorani and E. Tronc, Adv. Chem. Phys. 98 (1997) 283.

[19] F. Gazeau, J.C. Bacri, F. Gendron, R. Perynski, Y.L. Raikher, V.I. Stepanov and E.J. Dubois, Magn. 
Magn. Mater. 186 (1998) 175.

[20] R.S.D. Biasi and T.C. Devezas, J. Appl. Phys. 49 (1978 ) 2466 .

[21] R. Berger,J.C. Bissey, J. Kliava, H. Daubric and C. Estourn"es, J. Magn. Magn. Mater. 234 (2001) 535.

[22] R.D. Sánchez, M.A. López-Quintela, J. Rivas,A. González-Penedo, A.J. García-Bastida, C.A. Ramos, R.D. Zysler, S. Ribeiro Guevara, J. Phys. Condens. Matter. 11(1999) 5643.

[23] Yu.L. Raikher and V.I. Stepanov, Phys. Rev. B 50 (1994) 6250.

[24] J. Smit and H.G. Beljers, Phillips Res. Rept. 10 (1994) 113.

[25] A.H. Morrish, The Physical Principles of Magnetism, Wiley, New York (1965).

[26] E.D. Biasi, C.A. Ramos and R.D. Zysler, J. Magn. Magn. Mater 262 (2003) 235.

[27] A. Verma, O.P. Thakur,C. Prakash, T.C. Goel and R.G. Mendiratta, Mat. Sci. Eng. B 116 (2005) 1.

[28] A.A. Choni, A.I. Etyhhand and A.A. Mohamed, Proc. Int. Conf. Ferrites 5 (1980) 216.

[29] M.U. Islam, T. Abbas and M.A. Chaudhry, Mater. Lett. 53 (2002) 30.

[30] B.P. Ladgaokar and A.S. Vaingankar, Mater. Chem. Phys. 56 (1998) 280.

[31] S. Si, C. Li, X. Wang, D. Yu, Q. Peng and Y. Li, Cryst Growth Des. 5 (2005) 391.

[32] A. Sukhov, K.D. Usadel and U. Nowak, J. Magn. and Mag. Mat. 320 (2008) 31.

[33] R. Berger, J.C. Bissey and J. Kliava, J. Phys. Condens. Matter. 12 ( 2000$) 9347$.

[34] C.G. Verdes, B. Ruiz-Diaz, S.M. Thompson, R.W. Chantrell and A. Stancu, J. Appl. Phys. 89 (2001) 7475. 


\section{Figure Captions}

Table 1. Comparison of Magnetic parameters between the FMR measurements and VSM measurements.

Fig. 1. X-ray diffraction pattern of $\mathrm{Cu}_{1-x} \mathrm{Cd}_{x} \mathrm{Fe}_{2} \mathrm{O}_{4}$ nanoparticles.

Fig 2. Variation of average particle size and lattice parameter with cadmium content.

Fig. 3. FTIR spectra of $\mathrm{Cu}_{0.5} \mathrm{Cd}_{0.5} \mathrm{Fe}_{2} \mathrm{O}_{4}$ samples

Fig. 4. DTA-TG curves of $\mathrm{CuCdFe}_{2} \mathrm{O}_{4}$ mixture in air at a specified heating rate of $5^{\circ} \mathrm{C}$

Fig. 5. (a-c) The resonance spectra (FMR) of $\mathrm{Cu}_{1-x} \mathrm{Cd}_{x} \mathrm{Fe}_{2} \mathrm{O}_{4}$ powder as a function of the magnetic field in different temperature $(125 \mathrm{~K}, 280 \mathrm{~K}$ and $400 \mathrm{~K})$.

Fig. 6. Peak to peak line width vs temperature for the $\mathrm{Cd}_{\mathrm{x}} \mathrm{Cu}_{1-\mathrm{x}} \mathrm{Fe}_{2} \mathrm{O}_{4}$

Fig. 7. Resonance field vs temperature for the $\mathrm{Cd}_{\mathrm{x}} \mathrm{Cu}_{1-\mathrm{x}} \mathrm{Fe}_{2} \mathrm{O}_{4}$.

Fig. 8. Temperature vs resonance field in $\mathrm{Cd}_{0.3} \mathrm{Cu}_{0.7} \mathrm{Fe}_{2} \mathrm{O}_{4}$. 
Table 1. Comparison of Magnetic parameters between the FMR measurements and VSM measurements.

\begin{tabular}{|c|c|c|c|c|}
\hline $\mathrm{X}$ & $\begin{array}{c}\mu(\mathrm{FMR}) \text { in } \\
\mu_{\mathrm{B}}\end{array}$ & $\begin{array}{c}\mu(\mathrm{VSM}) \text { in } \\
\mu_{\mathrm{B}}\end{array}$ & $\begin{array}{c}\mathrm{H}_{\text {anis }}(\mathrm{FMR}) \\
\mathrm{kG}\end{array}$ & $\begin{array}{c}\mathrm{H}_{\text {anis }}(\mathrm{VSM}) \\
\mathrm{kG}\end{array}$ \\
\hline 0.3 & 15.595 & 15.6 & 9.38 & 9.25 \\
\hline 0.4 & 8.287 & 8.25 & 5.60 & 5.45 \\
\hline 0.5 & 12.468 & 12.45 & 5.95 & 5.8 \\
\hline 0.6 & 16.123 & 16.08 & 9.92 & 10.1 \\
\hline 0.7 & 11.263 & 11.23 & 9.5 & 9.5 \\
\hline
\end{tabular}




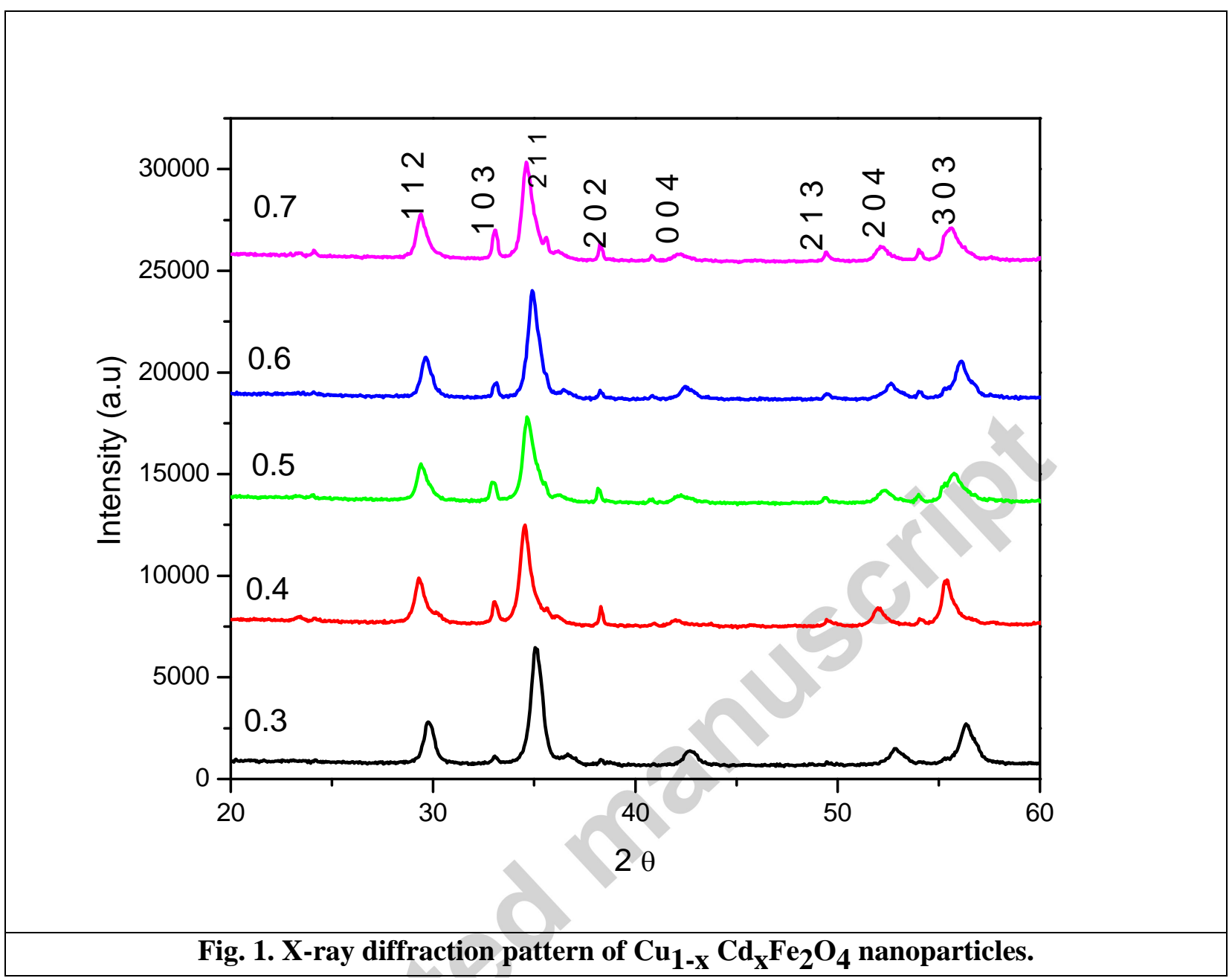




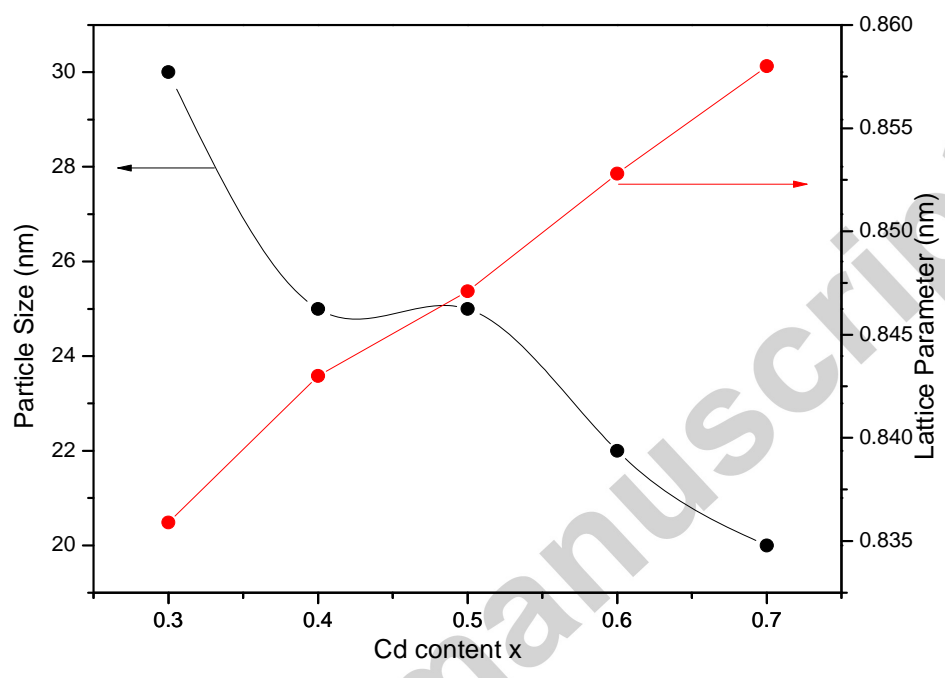

Fig. 2. Variation of average particle size and lattice parameter with cadmium content. 


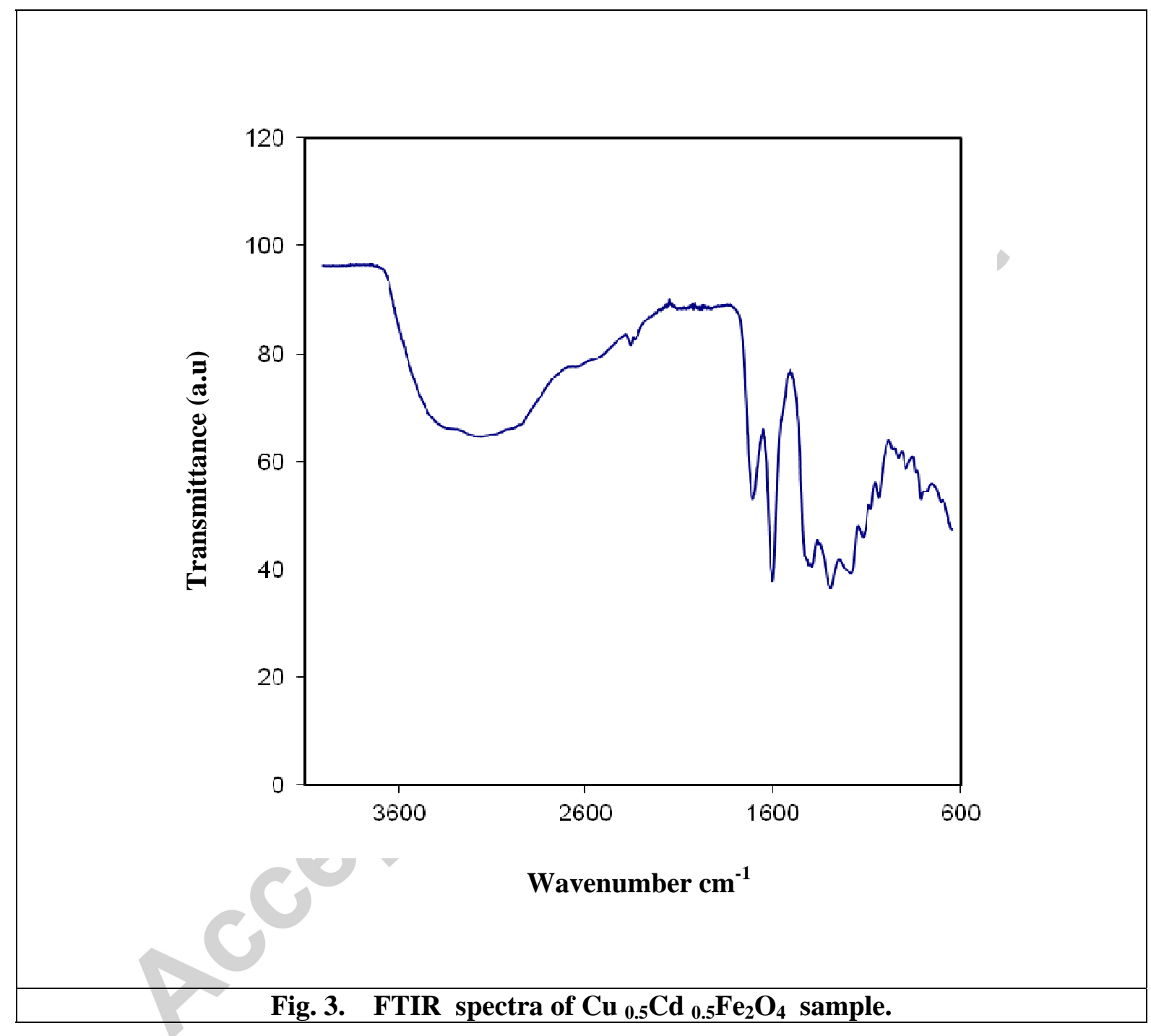




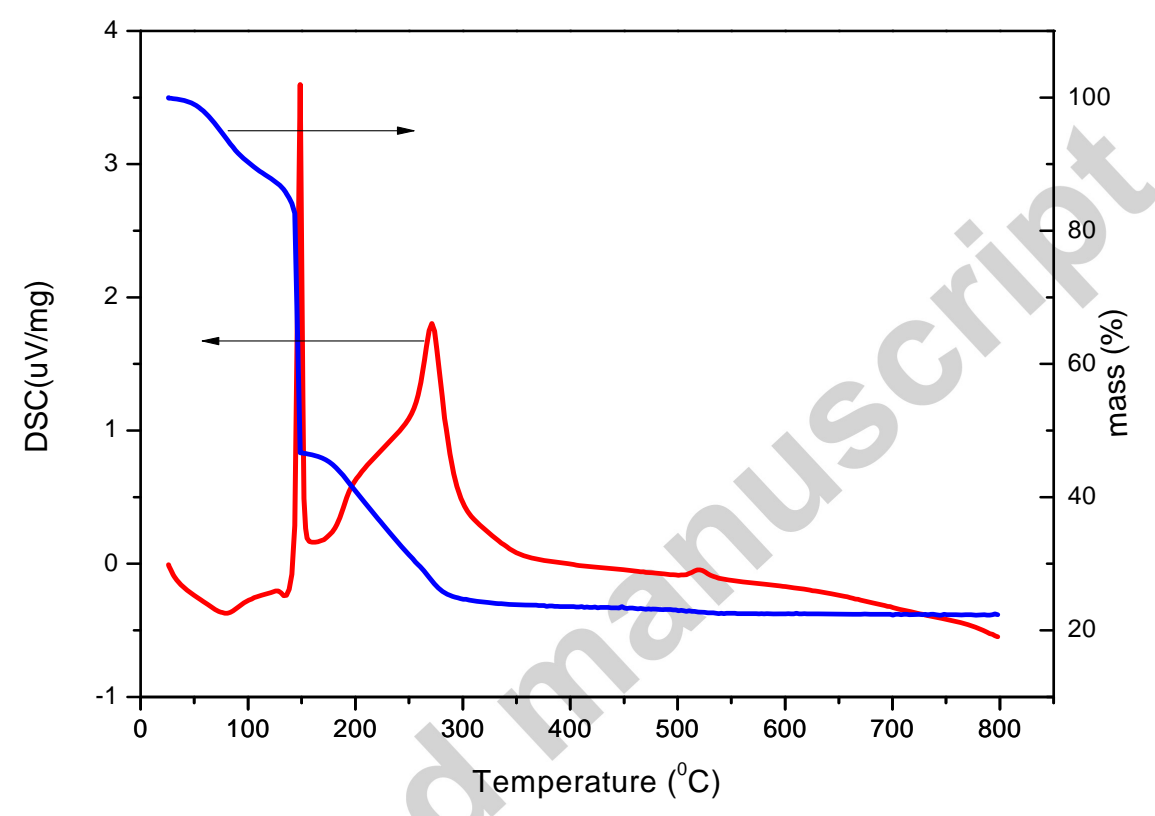

Fig. 4. DTA-TG curves of $\mathrm{CuCdFe}_{2} \mathrm{O}_{4}$ in air at a specified heating rate of $5 \% \mathrm{~min}$. 
$\mathrm{CdFe}_{2} \mathrm{O}_{4} ; \mathrm{mwp}=0.5 \mathrm{~mW} ; \mathrm{G}$ ain $=1 \times 10^{2} ; \mathrm{F}=9.48 \mathrm{GHz} ; \mathrm{Standard}$ cavity Temperature: $125 \mathrm{~K}$

Powder samples

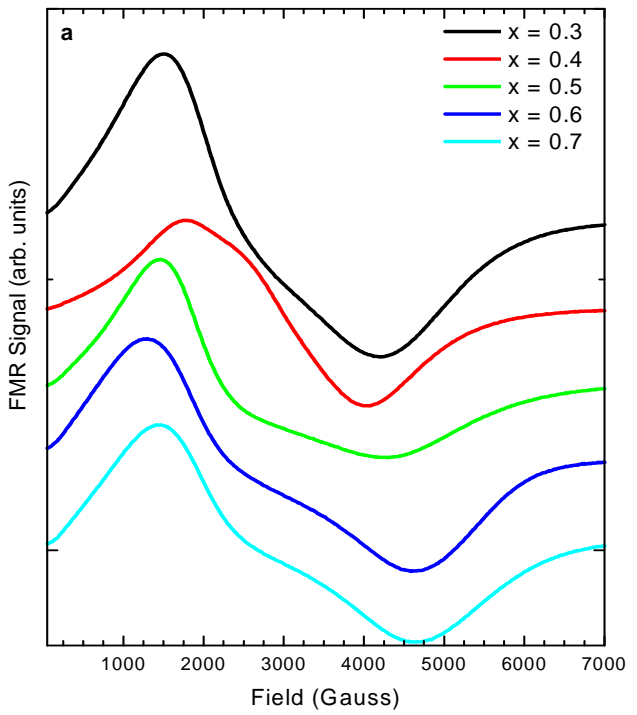

$\mathrm{CdFe}_{2} \mathrm{O}_{4} ; \mathrm{mwp}=0.5 \mathrm{~mW} ; \mathrm{Gain}=1 \times 10^{2} ; \mathrm{F}=9.48 \mathrm{GHz}$; Standard cavity Temperature: $280 \mathrm{~K}$

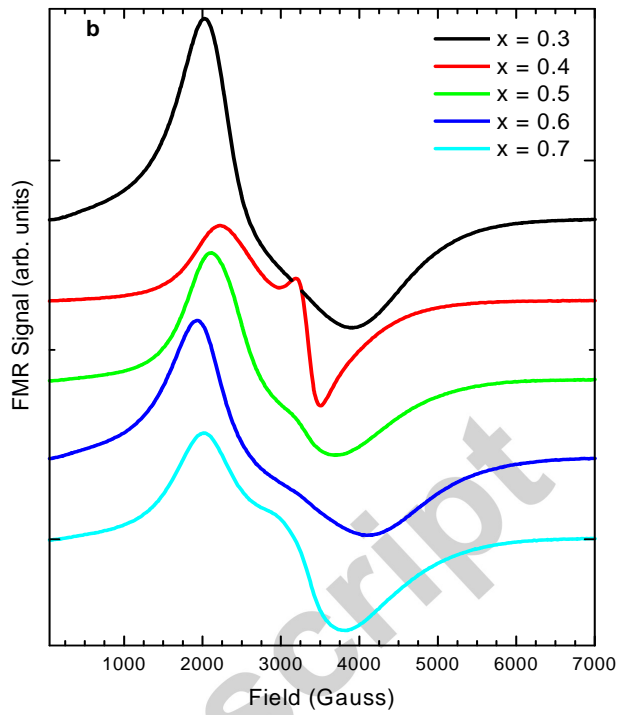

$\mathrm{CdFe}_{2} \mathrm{O}_{4} ; \mathrm{mwp}=0.5 \mathrm{~mW} ; \mathrm{G}$ ain $=1 \times 10^{2} ; \mathrm{F}=9.48 \mathrm{GHz} ;$ Standard cavity Temperature: $400 \mathrm{~K}$ Powder samples

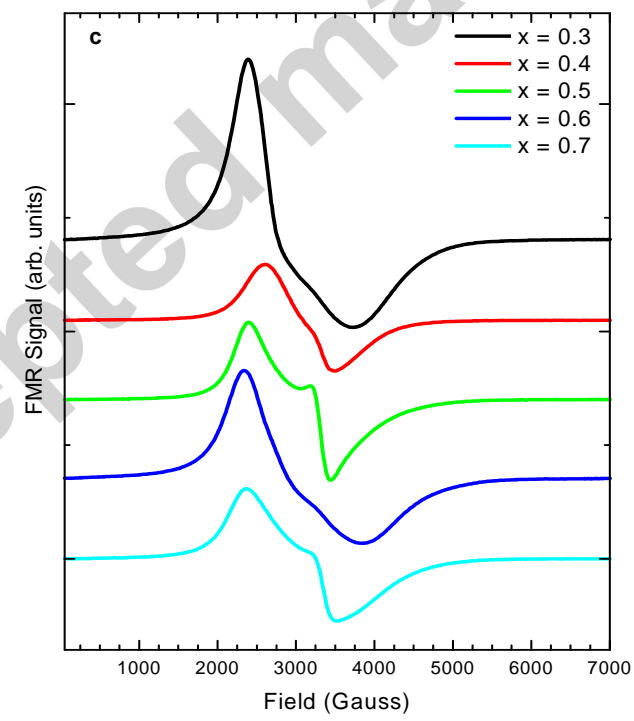

Fig. 5. (a-c) The resonance spectra (FMR) of $\mathrm{Cu}_{1-\mathrm{x}} \mathrm{Cd}_{\mathrm{x}} \mathrm{Fe}_{2} \mathrm{O}_{4}$ powder as a function of the magnetic field at different temperature $(125 \mathrm{~K}, 280 \mathrm{~K}$ and $400 \mathrm{~K})$. 


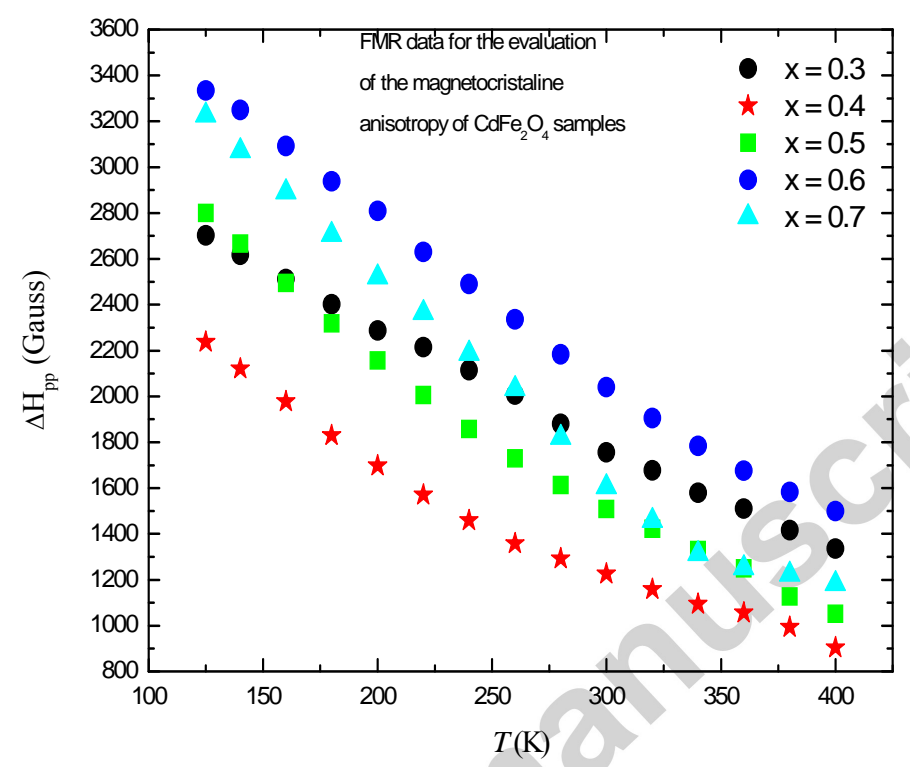

Fig. 6. Peak to peak line width vs temperature for the $\mathrm{Cd}_{\mathrm{x}} \mathrm{Cu}_{1-\mathrm{x}} \mathrm{Fe}_{2} \mathrm{O}_{4}$ 


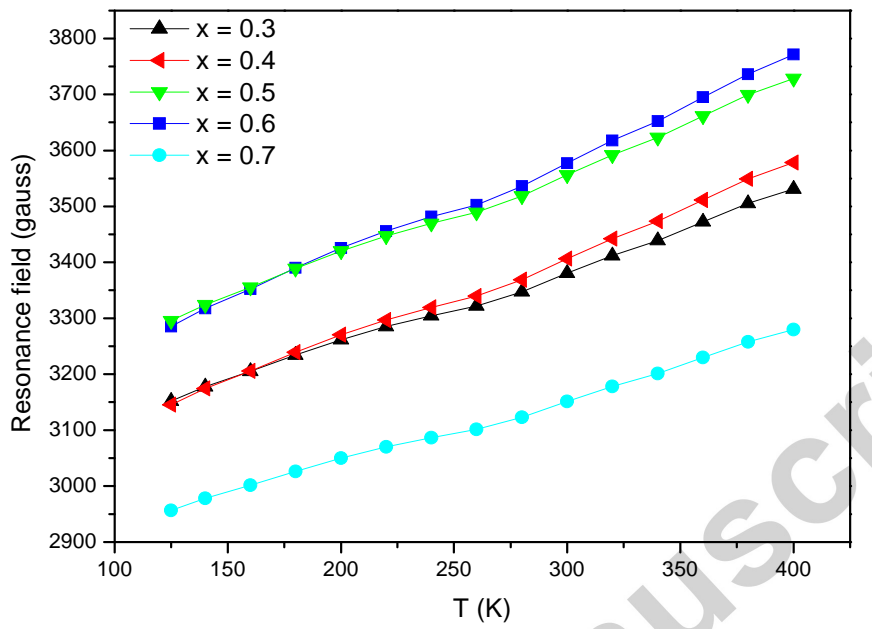

Fig. 7. Resonance field vs temperature for the $\mathrm{Cd}_{\mathrm{x}} \mathrm{Cu}_{1-\mathrm{x}} \mathrm{Fe}_{2} \mathrm{O}_{4}$. 


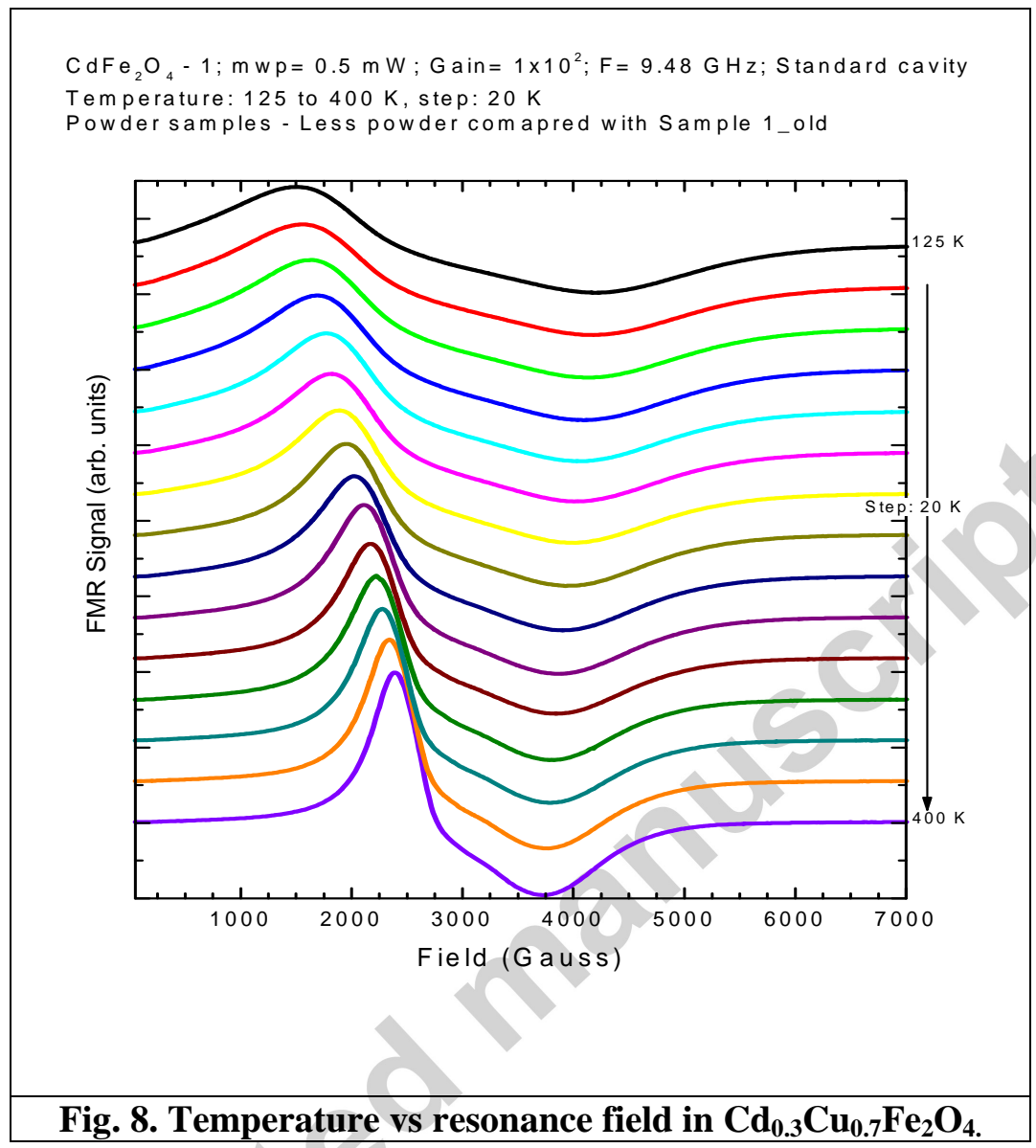




\begin{abstract}
This report presents the synthesis of copper cadmium ferrite $\left(\mathrm{Cu}_{1-x} \mathrm{Cd}_{x} \mathrm{Fe}_{2} \mathrm{O}_{4}, \mathrm{x}=0.3,0.4,0.5\right.$, 0.6 and 0.7 ) by citrate precursor method and its subsequent characterization by using X-ray diffraction (XRD), differential scanning caloriemetry, Infrared spectroscopy, Ferromagnetic resonance and vibrating sample magnetometer (VSM) techniques. XRD results confirm the single cubic spinel phase formation with the particle size of $40 \mathrm{~nm}$, which decreased up to $20 \mathrm{~nm}$ with increases in Cd content, while the lattice parameter increased with increase in $\mathrm{Cd}$ content. A significant change in the magnetic properties was observed in $\mathrm{CuFe}_{2} \mathrm{O}_{4}$ system with $\mathrm{Cd}$ doping. The line width and resonance field variation against change in temperature is noted and the data is fitted to the Linearlized model (LM) and Smit and Beljers (SB) model to finds out the parameters. A system with varying magnetic moment $\mathrm{Cd}$ doped copper ferrite were used as a nanoparticles system. The results recorded from the $\mathrm{SB}$ approach are quite in good agreement to that is observed in the magnetic measurements carried out by VSM.
\end{abstract}




\section{Highlights PCS_6440}

1. Copper cadmium ferrite compounds prepared by citrate precursor method.

2. XRD results confirm the single cubic spinel phase formation with the particle size of $20 \mathrm{~nm}$,

3. The lattice parameter increased with increase in Cd content.

4. A significant change in the magnetic properties was observed in $\mathrm{CuFe}_{2} \mathrm{O}_{4}$ system with Cd doping. 